\title{
HETEROGENEITY IN IRRIGATORS’ WTP AND WTA FOR WATER RELIABILITY
}

\author{
$\underline{\text { Anastasio J. Villanueva }}^{\mathrm{a}, \mathrm{b}, *}$ and José A. Gómez-Limón ${ }^{\mathrm{b}}$
}

a Institute of Agricultural Research and Training (IFAPA), Centre Camino de Purchil, (anastasioj.villanueva@juntadeandalucia.es, Granada, Spain); $b$ WEARE-Water, Environmental and Agricultural Resources Economics Research Group, University of Cordoba, (jglimon@uco.es, Cordoba, Spain)

\begin{abstract}
This paper is focused on the valuation of irrigation water supply reliability. We assess WTP and WTA for improvements and worsenings in irrigation water supply reliability, checking for the first time the disparity between average WTA and average WTP for this attribute of irrigation water supply. This assessment relies on a field experiment among farmers in an irrigated area located in southern Spain that is suffering a serious deterioration of water supply reliability because of climate change. Results obtained show average WTP estimates for moderate and significant improvements are $€ 16.5$ and $€ 18.5 /$ ha/year, respectively, while the average WTA estimates for moderate and significant worsenings are $€ 765.6$ and $€ 881.1 /$ ha/year. This indicates a very high WTA/WTP ratio of 46.4 and 47.6 for moderate and significant changes, much higher than those obtained in previous studies. Possible reasons which may explain such a disparity include reasons within neoclassical economic theory and endowment effects.
\end{abstract}

Keywords: Climate change, Irrigation water demand; Water supply guarantee; Choice experiment; Water policy

\section{Introduction}

Climate change is worsening water supply reliability, seriously jeopardizing the economic sustainability of the irrigators' farms since this results in lower and more volatile farm income. This is especially true in semi-arid regions, which are characterized by high resource scarcity. Under these circumstances, supplyside policy instruments can hardly represent an option to adapt to new scenarios of acute scarcity, hence demand-side policy instruments often represent the only possible approach.

To efficiently design demand-side water management instruments, information on water users' welfare change associated with improvements (i.e., as a result of the implementation of policy instruments) and worsenings (i.e., if no action is taken within a climate change context) in water supply reliability is key. However, there is scarce literature in this field regarding irrigated agriculture. To the authors' knowledge, only a few studies have valued so far irrigation water supply reliability [see Guerrero-Baena et al. (2019), for a recent review]. All these studies measure irrigators' welfare change in terms of willingness to pay (WTP) for improvements in water supply reliability, as suggested by the official guidance which considers that benefit-cost analyses should rely on WTP. However, more recent literature cast doubts on this guidance, suggesting that the use of WTP measures to estimate damages may underestimate the economic value of welfare changes, thus leading to a suboptimal policy design [Koetse y Brouwer (2016)]. This calls for the use of willingness-to-accept (WTA) formats (over WTP ones) to estimate the progressive deterioration of water supply reliability due to climate change in a no-policy scenario. Nevertheless, this valuation approach has not been implemented yet, and no reliable value estimation of climate changeinduced reliability worsening is available in the existing literature.

Against this framework, the primary objective of the paper is to analyze the disparity between the WTP for improved irrigation water supply reliability and the WTA for being compensated for deterioration of water supply guarantee. These two valuation assessments rely on choice experiments (CE) and will allow us to provide new insights on the disparity between WTP and WTA and to discuss the reasons behind this gap, and test if this gap is heterogeneous among irrigators.

\section{Methodological approach}

\subsection{Case study and valuation scenarios}

The case study of Santaella Irrigators Community (IC), located in the Guadalquivir River Basin (GRB, southern Spain), has been selected. This is a large irrigation district (15,500 hectares) using surface water resources delivered by the GRB agency. Santaella IC is operating with modern and efficient irrigation technologies, with sprinkler and drip irrigation systems being the most widely used. The main crops are olive groves, sunflower, vegetables (mainly garlic and onion), wheat, and cotton. The IC's water management costs are charged to irrigators separately through a binomial bill including two components based on the area (fixed costs imputation, being $€ 150 /$ ha/year approx. on average) and volumetric (variable costs imputation, being $€ 0.04 / \mathrm{m}^{3} /$ year approx. on average) criteria.

As for most of the irrigation districts in the GRB, Santaella IC does not commonly receive water allotments about the legal concession of $5,000 \mathrm{~m}^{3} / \mathrm{ha} /$ year to which it is entitled. From the series of water allotments in Santaella IC from 1996 to 2015, the normal distribution function well-fitted the data [Guerrero-Baena et 
al. (2019)]. Fig. 1 shows the cumulative density function of the current scenario of water allotments, and simulated improved (II,I2, and I3) and worsened (WI and W2) scenarios of water supply reliability which were used in the study. $I 1, I 2$, and $I 3$ refer to situations where the gap or difference between concession and allotment is reduced each year by $25 \%, 50 \%$, and $75 \%$, respectively, compared to the current situation. WI and $W 2$ refer to situations where such a gap is increased by $25 \%$ and $50 \%$. These scenarios focus our analysis of irrigators' WTP for improvements and WTA for worsenings, respectively, in their water supply reliability.

Figure 1. Normal cumulative density functions in the Santaella IC in the current scenario, improved and worsened scenarios $(I 1, I 2, I 3, W 1$, and W2) of irrigation water supply reliability

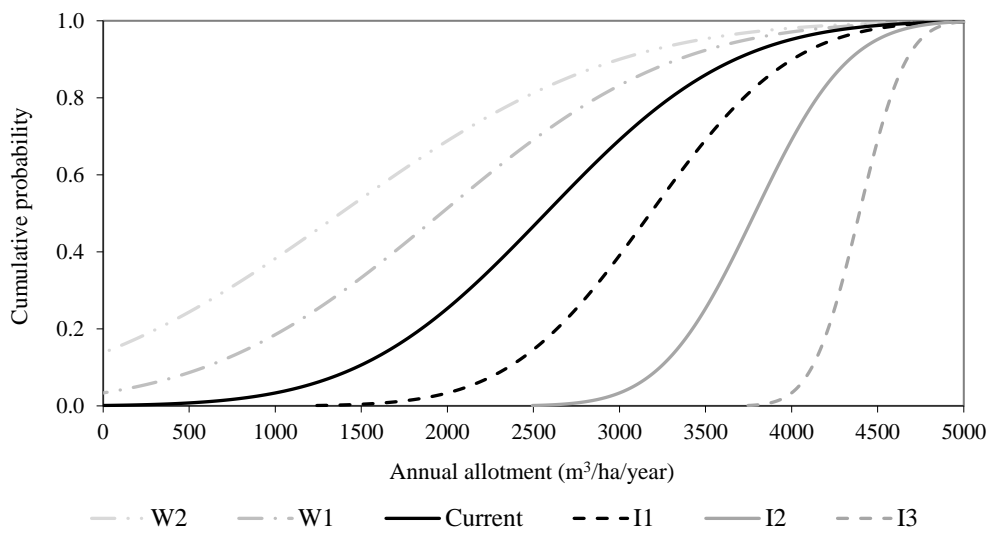

\subsection{Choice experiment and econometric specification}

The CE approach used included the administration of two consecutive CE exercises: one focused on WTP for improved water supply reliability (CE_WTP) and another on WTA for worsened water supply reliability (CE_WTA). Both have the same attributes: two non-monetary attributes related to the normal probability density function (PDF) describing water supply reliability $-\mu$ and $\sigma^{2}$ parameters-, and one monetary attribute. The definition of the non-monetary attributes relies on a mean-variance approach, as justified in Guerrero-Baena et al. (2019). Thus, attribute levels considered are linked to the changes referred to the abovementioned scenarios of improved and worsened water supply reliability, in addition to the PDF for water supply of the current situation, as shown in Table 1. For a full description of the CE, experimental design, and sampling, please consult Guerrero-Baena et al. (2019).

Table 1. Attributes and levels used in the choice experiments

\begin{tabular}{|c|c|c|c|}
\hline \multirow[t]{2}{*}{ Attribute } & \multirow[t]{2}{*}{ Explanation } & \multicolumn{2}{|l|}{ Levels } \\
\hline & & $\begin{array}{l}\text { CE exercise focusing on WTP for } \\
\text { improvements }\left(C E_{-} W T P\right)\end{array}$ & $\begin{array}{l}\text { CE exercise focusing on WTA for } \\
\text { worsenings (CE_WTA) }\end{array}$ \\
\hline \multirow[t]{2}{*}{$\begin{array}{l}\mu \\
\text { parameter }\end{array}$} & \multirow{2}{*}{$\begin{array}{l}\mu \text { parameter of the } \\
\text { normal PDF fitting } \\
\text { the six scenarios } \\
\text { considered of water } \\
\text { supply reliability of } \\
\text { the irrigation district }\end{array}$} & $\begin{array}{l}\mu_{S Q}=2,572 ; \mu_{I 1}=3,179 ; \mu_{I 2}= \\
3,786 ; \mu_{I 3}=4,393\left(\mathrm{~m}^{3} / \text { ha/year }\right)\end{array}$ & $\begin{array}{l}\mu_{S Q}=2,572 ; \mu_{W 1}=1,965 ; \mu_{W 2}= \\
1,378\left(\mathrm{~m}^{3} / \mathrm{ha} / \text { year }\right)\end{array}$ \\
\hline & & $\begin{array}{l}\text { (i.e., } \mu \text { parameter of the normal PDF of } \\
\text { the situation where the gap between the } \\
\text { allotments and the concession is } \\
\text { reduced by } 25 \%, 50 \% \text {, and } 75 \% \text {, } \\
\text { respectively) }\end{array}$ & $\begin{array}{l}\text { (i.e., } \mu \text { parameter of the normal PDF of } \\
\text { the situation where the gap between the } \\
\text { allotments and the concession is } \\
\text { increased by } 25 \% \text {, and } 50 \% \text { ) }\end{array}$ \\
\hline \multirow[t]{2}{*}{$\begin{array}{l}\sigma^{2} \\
\text { parameter }\end{array}$} & \multirow{2}{*}{$\begin{array}{l}\sigma^{2} \text { parameter of the } \\
\text { normal PDF fitting } \\
\text { the six scenarios } \\
\text { considered of water } \\
\text { supply reliability of } \\
\text { the irrigation district }\end{array}$} & $\begin{array}{l}\sigma_{S Q}^{2}=741,321 ; \sigma_{I 1}^{2}= \\
417,316 ; \sigma_{I 2}^{2}=185,761 ; \sigma_{I 3}^{2}= \\
46,225\left(\left(\mathrm{~m}^{3} / \text { ha/year }\right)^{2}\right)\end{array}$ & $\begin{array}{l}\sigma_{S Q}^{2}=741,321 ; \sigma^{2}{ }_{W 1}= \\
1,158,637 ; \sigma^{2}{ }_{W 2}=1,604,782 \\
\left(\left(\mathrm{~m}^{3} / \text { ha/year }\right)^{2}\right)\end{array}$ \\
\hline & & $\begin{array}{l}\text { (i.e., } \sigma^{2} \text { parameter of the normal PDF of } \\
\text { the situation where the gap between the } \\
\text { allotments and the concession is } \\
\text { reduced by } 25 \%, 50 \% \text {, and } 75 \% \text {, } \\
\text { respectively) }\end{array}$ & $\begin{array}{l}\text { (i.e., } \sigma^{2} \text { parameter of the normal PDF of } \\
\text { the situation where the gap between the } \\
\text { allotments and the concession is } \\
\text { increased by } 25 \% \text {, and } 50 \% \text { ) }\end{array}$ \\
\hline $\begin{array}{l}\text { Monetary } \\
\text { attribute } \\
(E U R)\end{array}$ & $\begin{array}{l}\text { Yearly additional } \\
\text { payment paid by the } \\
\text { farmer }\end{array}$ & $\begin{array}{l}2 \%, 5 \%, 10 \%, 20 \%, 30 \%, 50 \% \\
(€ / \text { ha/year) of current total payment for } \\
\text { irrigation water to pay for improved } \\
\text { reliability }\end{array}$ & $\begin{array}{l}2 \%, 5 \%, 10 \%, 20 \%, 30 \%, 50 \% \\
\text { (€/ha/year) of current total payment for } \\
\text { irrigation water to be received in } \\
\text { exchange for worsened reliability }\end{array}$ \\
\hline
\end{tabular}


As econometric specification, random parameter logit (RPL) specifications with an error component were used. For a comprehensive description of the DCE method, we refer to Hensher et al. (2005).

\section{Results}

Table 2 shows the result of the MXL models, drawn on data on farmers' preferences toward improved (MXL_WTP) and worsened (MXL_WTA) irrigation water supply reliability. As shown, the models are highly significant and show notable goodness-of-fit (pseudo-R ${ }^{2}$ of 0.56 and 0.73 for MXL_WTP and MXL_WTA, respectively). All attribute parameters are highly significant and have the expected sign, i.e.: positive for increasing mean, $\mu$; negative for increasing variance, $\sigma^{2}$; negative for payments for increased reliability (EUR in MXL_WTP) and positive for money received in exchange for decreased reliability (EUR in MXL_WTA). Standard deviations are significant for three and one out of the four random parameters of MXL_WTP and MXL_WTA, respectively, meaning that there is heterogeneity of farmers' preferences toward water supply reliability (especially for improvements in reliability). The alternativespecific constants (ASCsq) are significant for the two models: negative in MXL_WTP (meaning disutility associated with the SQ alternative, for reasons unrelated to the attributes considered) and positive in MXL_WTA (meaning utility associated with the SQ alternative). This indicates a general willingness to choose alternatives representing improved water supply reliability (MXL_WTP) and a general unwillingness to choose alternatives representing worsened water supply reliability (MXL_WTA). Finally, an interaction term of the monetary attribute and the order of the CE exercise (taking the value 1 when the farmer first faced the CE_WTP, and 0 when s/he faced the CE_WTA at first) was found to be negative and significant only in the MXL_WTP, meaning that farmers who faced the CE_WTP at first had lower disutility for payments for improved water supply reliability. Order effects were also explored for the other attributes, but no other significant interaction was found (models are available upon request).

Table 2. Mixed logit models

\begin{tabular}{|c|c|c|c|c|c|c|c|c|}
\hline & \multicolumn{4}{|c|}{ MXL_WTP } & \multicolumn{4}{|c|}{ MXL_WTA } \\
\hline & \multicolumn{2}{|c|}{ Mean } & \multicolumn{2}{|l|}{ SD } & \multicolumn{2}{|l|}{ Mean } & \multicolumn{2}{|c|}{ SD } \\
\hline & Coef. & $S E$ & Coef. & $S E$ & Coef. & $S E$ & Coef. & $S E$ \\
\hline$\overline{\mu\left(1000 \mathrm{~m}^{3} / \text { ha/year }\right)}$ & $1.052^{*}$ & 0.417 & $2.182^{* * *}$ & 0.523 & $2.334^{* * *}$ & 0.421 & 0.176 & 3.060 \\
\hline$\sigma^{2}\left(100,000\left(\mathrm{~m}^{3} / \text { ha/year }\right)^{2}\right)$ & $-0.792^{* *}$ & 0.242 & 0.684 & 0.411 & $-0.774^{* * * *}$ & 0.139 & 0.311 & 0.204 \\
\hline EUR & $1.372^{* * *}$ & 0.335 & $2.336^{* * *}$ & 0.255 & $-2.193^{* * *}$ & 0.526 & $1.085^{\text {** }}$ & 0.357 \\
\hline EUR $\times$ First CE_WTP $(0,1)$ & $-0.874^{*}$ & 0.425 & & & -2.678 & 3.331 & & \\
\hline ASCsq & $-4.286^{* * *}$ & 1.111 & $8.045^{* * *}$ & 1.724 & $5.570^{* * *}$ & 1.074 & 0.986 & 4.248 \\
\hline Error component & -2.048 & 2.156 & & & $4.637^{* * *}$ & 1.110 & & \\
\hline$\overline{\text { Log-likelihood (LL) }}$ & & -566.25 & & & & 1291.97 & & \\
\hline McFadden Pseudo ${ }^{2}$ & & 0.562 & & & & 0.734 & & \\
\hline $\mathrm{AIC} / \mathrm{N}$ & & 0.980 & & & & 0.602 & & \\
\hline Observations (individuals) & & $176(196)$ & & & 117 & $6(196)$ & & \\
\hline
\end{tabular}

${ }^{* * * * * * * *}$ denote significance at $0.1 \%, 1 \%$, and $5 \%$ level, respectively.

Using the information included in the models shown above, we can derive welfare estimates (WTP and WTA) for scenarios with equivalent changes (improvements and worsenings). Table 3 shows the welfare estimates for the whole sample, and for split samples according to which CE the farmer faced first. The average WTP estimates for moderate (II) and significant improvements (I2) are $€ 16.5$ and $€ 18.5 /$ ha/year, while the average WTA estimates for moderate $(W 1)$ and significant worsenings $(W 2)$ are $€ 765.6$ and $€ 881.1 / \mathrm{ha} /$ year. This indicates a very high WTA/WTP ratio of 46.4 and 47.6 for moderate and significant changes.

Considering the CE order effects, the WTP estimates raise to $€ 19.4$ and $€ 21.4 / \mathrm{ha} /$ year for moderate and significant improvements for those who first faced the CE_WTP, and decline to $€ 14.4$ and $€ 16.4 /$ ha/year for such scenarios for those who first faced CE_WTA. Accordingly, the abovementioned ratio decreases (increases) for the former (latter) to values around 40 (53).

Table 3. Welfare estimates (simulations of median values using Krinsky and Robb (1986) 's procedure)

\begin{tabular}{lllccc}
\hline \multicolumn{2}{l}{ Sample } & \multicolumn{1}{l}{ Change } & WTP* $^{*}$ & WTA* $^{*}$ & WTA/WTP \\
\hline Whole & \multirow{2}{*}{ sample } & Moderate (I1 or W1) & 16.5 & 765.6 & 46.4 \\
(N=196) & & Significant (I2 or W2) & 18.5 & 881.1 & 47.6 \\
\hline First & CE_WTP=1 & Moderate (I1 or W1) & 19.4 & 765.6 & 39.6 \\
(N=99) & & Significant (I2 or W2) & 21.4 & 881.1 & 41.2 \\
\hline First & CE_WTP=0 & Moderate (I1 or W1) & 14.4 & 765.6 & 53.1 \\
(N=97) & & Significant (I2 or W2) & 16.4 & 881.1 & 53.7 \\
\hline
\end{tabular}

*All significant at $0.1 \%$ level. 
Using parameters at an individual level, the ratio Z=(WTA-WTP)/WTA was calculated to look for groups of farmers according to the WTA/WTP disparity. The number of individuals grouped within intervals of $Z$ for moderate $(\mathrm{Z} 1)$ and significant changes (Z2) in irrigation water supply reliability is shown in Table 4. The results show that $45 \%(n=89)$ of the farmers present $Z=1$, due to $W T P=0$, regardless of the change intensity. Another $44 \%$ ( $n=86$ for $Z 1$, and $n=87$ for $Z 2$ ) present $Z$ values within $0.5-0.99$ interval, meaning a very high WTA/WTP disparity, with the remaining $10-11 \%$ of farmers $(n=21$ for $Z 1$, and $n=20$ for Z2) showing values of $\mathrm{Z}$ below 0.5 , meaning levels of WTA/WTP disparity not extreme.

Table 4. Number of individuals according to the ratio $Z=(W T A-W T P) / W T A$ at an individual level

\begin{tabular}{lcc}
\hline Intervals of $\mathbf{Z}$ & Moderate changes $(\mathbf{Z 1})$ & Significant changes $(\mathbf{Z 2})$ \\
\hline 1.00 & 89 & 89 \\
$0.50-0.99$ & 86 & 87 \\
$0.90-0.99$ & 63 & 68 \\
$<0.50$ & 21 & 20 \\
\hline Total & 196 & 196 \\
\hline
\end{tabular}

\section{Concluding remarks}

The results join previous findings showing the disparity between WTA and WTP values, being the first to show this with regard to farmers' preferences toward irrigation water supply reliability. However, the level of disparity found is extreme compared to those levels obtained from the vast majority of the previous studies [Tunçel y Hammitt (2014)]. Possible reasons which may explain such a disparity include reasons within neoclassical economic theory and endowment effect.

Among reasons drawn from the neoclassical economic theory, income effects and substitutability outstand for the case under study. With regard to income effects, since the level of water supply reliability in the selected case study is set by the river basin water authority based on current water infrastructure, in our study irrigators could act as 'quantity takers' (i.e., there are exogenous constraints over the available amount of the good to be consumed/used), thus suggesting that significant income effects could be causing a wide WTA-WTP gap in our case. With regard to substitutability, although irrigation water supply reliability is a non-market good in the selected case study (it cannot be modified in exchange for money), irrigators have some alternatives to mitigate problems related to supply reliability. For instance, in the case of water shortages, farmers can sow crops with lower water needs, buy additional water amounts in the spot water market, or improve irrigation efficiency at farm level. All these options could be considered as substitutes for an improved water supply reliability, thus suggesting that substitutability may play a role in the WTAWTP disparity found. However, there is no evidence on the actual substitution elasticity between these options and thus the level of influence of substitution effects on such a disparity.

Finally, the wide WTA-WTP disparity may be a manifestation of 'loss aversion', evidencing 'endowment effects' [Thaler (1980)] related to the notion that irrigators value losses (i.e., worsened water supply reliability) higher than gains (i.e., improved water supply reliability), thus requiring higher compensations (WTA) to give up an asset (the current level of reliability) that they already possess. Applied to our case study, it is arguable that the irrigators do not want to provide signals of lower water supply reliability needs as this may entail a reduction in the water rights given by the agency. In this regard, the uncertainty linked to climate change most probably plays a role on the magnitude of the 'endowment effect' as irrigators may differ in the perceived losses and gains associated respectively with worsened and improved water supply reliability. This opens up an avenue for further research focusing on how uncertainty about losses and gains influence the WTA-WTP asymmetry.

\section{References}

Guerrero-Baena, M.D., Villanueva, A.J., Gómez-Limón, J.A. y Glenk, K. (2019). "Willingness to pay for improved irrigation water supply reliability: An approach based on probability density functions". Agricultural Water Management, 217: 11-22.

Hensher, D., Hanley, A., Rose, J.M. y Greene, W.H. (2005). Applied Choice Analysis: A Primer. Cambridge University Press, Cambridge, UK.

Koetse, M.J. y Brouwer, R. (2016). "Reference dependence effects on WTA and WTP value functions and their disparity". Environmental \& Resource Economics, 65(4): 723-745.

Thaler, R. (1980). "Toward a positive theory of consumer choice". Journal of Economic Behavior \& Organization, 1(1): 39-60.

Tunçel, T. y Hammitt, J.K. (2014). "A new meta-analysis on the WTP/WTA disparity". Journal of Environmental Economics and Management, 68(1): 175-187. 